\title{
Production of Polyhydroxyalkanoates (PHA) for Biomedical Application using Sugar Industry Waste and Native Micro Flora via Biphasic System.
}

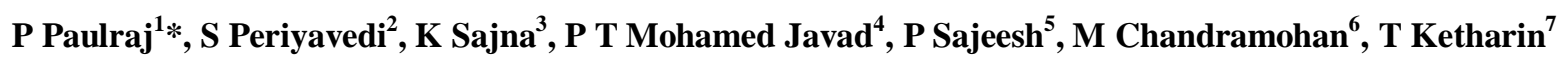 \\ Department of Biomedical Sciences, Faculty of Medicine, MAHSA University, Bandar Saujana Putra, \\ Selangor, Malaysia \\ *Corresponding author E-mail: paulraj@mahsa.edu.my
}

\begin{abstract}
Plastics are synthetic polymers that changed our daily life due to their applications. But it's increasing environmental problems had made the researchers find the alternative way such as usage of biodegradable plastics like Polyhydroxyalkanoates (PHA) which has similar properties to the conventional plastic. In this research production and characterization of PHAs using sugar industry wastes as a sole carbon source was carried in order to reduce the cost of production of PHA. Isolation of heterotrophic native micro flora from soil sample contaminated with sugar effluent for amylolytic and cellulolytic activity with PHA production potentials was carried out. Suitable conditions for PHA accumulation were optimized with 1X and 2X MSM with sugar effluent as a sole carbon source and bacteriostatic antibiotics as an inducer using bi-phasic system. A total of 14 different heterotrophic native bacterial strains were isolated, among them, 4 isolates showed starch hydrolytic property, 7 isolates showed cellulolytic activity and 7 were PHA producers. The strain with the highest PHA accumulation $(99.99 \mu \mathrm{g} / \mathrm{mL}$ of culture) in 2X MSM with sugar effluent within 6 hours was considered as a potential strain (53\% of PHB CWD). The isolate was confirmed as Chryseobacterium Sp. using 16S rRNA sequencing.
\end{abstract}

Keywords: Polyhydroxyalkanoates (PHA), Biopolymer, Sugar industry waste, Chryseobacterium, andPoly (3-hydroxybutyrate-co-3hydroxyvalerate).

\section{Introduction}

Plastics are inevitable in everyday life in the form of disposable utensils, packaging furniture, machinery housings and accessories for enhancing the life quality and comfort. Besides that, plastics are also known as a synthetic polymer which is one of the greatest conceptions of mankind that has significantly changed our daily life due to their usages in the industrial, domestic and environmental application. This widespread applications of plastics are due to their favourable stability, durability, shape and suitable mechanical and its thermal properties(Khanna and Srivastava, 2009).

Currently, the worldwide demand for the plastics has caused a serious environmental problem. The slow degradation of these non-biodegradable plastics which may persist in the environment for hundreds of years (Law et al., 2003). Therefore, an alternative way to decrease the environmental impacts of non-biodegradable plastics is to replace with biodegradable plastics. In addition to being biodegradable, they have further advantages of being produced by using renewable sources (Nath et al., 2008; Flieger et al., 2003).

Bio-based materials such as polyamides, polysaccharides, polyoxesters, polythioesters, polyanhydrides, polyisoprenoids and polyphenols are the potential candidates for the substitution of synthetic plastics (Steinbuchel, 2001). Biodegradable plastics which is known as plastics that decomposed by the action of living organism usually bacteria. Among the biodegradable plastics polyhydroxyalkanoates (PHAs) or otherwise known as biological polyesters have been draw in the attention due to their similar properties to conventional plastics and their biodegradable proper- ties. Microbial polyesters which contain hydroxyacyl monomers are termed as polyhydroxyalkanoates (PHAs), which are known as intracellular carbon reserves (Otari and Ghosh, 2009).

Polyhydroxyalkanoates (PHAs) form a large group of linear, aliphatic polyesters that can be obtained from renewable sources. The material's properties exhibited by polyhydroxyalkanoates (PHAs) which ranging from stiff, brittle to semi-rubber like makes it a close substitute for the synthetic plastics and gives wide range of final products.Poly (3-hydroxybutyrate-co3hydroxyvalerate) $\mathrm{P}$ (3HB-co-HV) has lower crystallinity and decreased stiffness, being more flexible and tougher than Poly (3hydroxybutyrate(P (3HB)) (Lee, 1996). Polyhydroxyalkanoates (PHAs) has more wide range of potential applications because of its desired features such as biocompatibility, biodegradability, thermos processable and negligible cytotoxicity to the cells. Biomaterials such as $\mathrm{P}(3 \mathrm{HB})$ and $\mathrm{P}(3 \mathrm{HB}-\mathrm{co}-3 \mathrm{HHx})$ were extensively studied PHA that used in the applications of tissue engineering and controlled drug released (Xiong et al., 2010). In addition to that PHAs are well studied for its biomedical applications with lots of patents as reported by Paulraj et al., 2018. The present study was aimed to produce polyhydroxyalkanoates (PHAs) from native micro flora using sugar industry effluent as a carbon substrate. 


\section{Materials and methods}

\subsection{Isolation of native micro flora.}

\subsubsection{Collection of soil sample and sugar industry effluent.}

Soil samples which are highly contaminated with sugar industry effluent were collected from Central Sugar Refinery (CSR) SDN BHD., Shah Alam, Selangor, Malaysia. The samples were collected using sterile zipper bags and transported to the laboratory for the isolation and screening of cellulolytic and amylolytic PHA producing bacterial strains. The samples and effluent were stored at $4^{\circ} \mathrm{C}$ prior to use.

\subsubsection{Isolation of heterotrophic native microorganism.}

One gram of soil sample was suspended into $100 \mathrm{~mL}$ of sterile saline water and shaken vigorously for 15 to 20 minutes. Then, the suspension was serially diluted in sterile saline water until $10^{-8}$. Aliquots of $1 \mathrm{~mL}$ of each diluted sample were pour plated in nutrient agar plates. Three replicates were done for each dilution and the plates were incubated at $37^{\circ} \mathrm{C}$ for 24 hours. After incubation, the developed colonies in the plates were counted and the mean number of colonies per triplicatesof plates were determined. The total number of heterotrophic bacteria in soil (CFU/g) was determined. Besides that, colonies which developed on the agar plates were differentiated by shape, size, margin, elevation gram's reaction and colour appearance. The colonies of different morphological characteristics were picked up and purified by streaking on sterile nutrient agar plates.

\subsubsection{Maintenance of bacterial strains.}

The selected pure bacterial cultures which obtained were maintained in nutrient agar slants at $4^{\circ} \mathrm{C}$ and sub-cultured it for every 7 to 10 days throughout the experiment for routine analysis. One set of pure cultures were maintained in glycerol stock at $-20^{\circ} \mathrm{C}$ and another set were maintained at $-80^{\circ} \mathrm{C}$ for long-term storage as the stock culture.

\subsection{Qualitative screening of bacterial strains for amylolytic and cellulolytic Activity.}

\subsubsection{Screening of bacterial strains for starch hydrolysis}

The selected bacterial strains which were obtained was streaked on five sets of starch agar plates and incubated at $37^{\circ} \mathrm{C}$ for up to five days (24h, 48h, 72h, 96h and 120h). Hydrolytic activities were confirmed by using Gram's Iodine reagent. The plates after incubation were flooded with Gram's Iodine reagent and allowed for 2 to 5 minutes where the positive strains were identified by clear halo zone surrounding the bacterial colonies with the dark blue background (Mishra and Behera, 2008).

\subsubsection{Screening of bacterial strains for cellulolytic activity.}

The bacterial strains were streaked on five sets of Carboxymethylcellulose (CMC) agar plates and incubated at $37^{\circ} \mathrm{C}$ for five consecutive days. Cellulolytic activities were detected by using Congo red, where the plates were flooded with freshly prepared $1 \%$ of Congo red stain for 20 minutes. Then, rinsed the plates with $1 \mathrm{M}$ sodium chloride. The positive strains showing clear zones around thecolony indicates positive cellulolytic activity (Johenson and Krause, 2014).

\subsection{Qualitative screening for PHA production.}

\subsubsection{Screening of bacterial strains for PHA accumulation.}

The bacterial strains were qualitatively screened for PHA accumulation by using Nile blue staining method (Kitamura and Doi, 1994). The bacterial strains were grown as single colony on Mineral salt media (MSM) plates with varying carbon and nitrogen concentration and incubated at $37^{\circ} \mathrm{C}$ for four consecutive days (24h, 48h, 72h and 96h). Freshly prepared Nile blue solution was spread all over the colonies after incubation, shaken gently and the plates were kept undisturbed for 20 minutes at room temperature. The plates were washed with $90 \%$ ethanol to remove excess stain. The stained bacterial colonies exposed under Ultraviolet transilluminator to detect PHA accumulation. Positive PHA producers have shown a bright orange fluorescence color.

\subsection{Quantitative screening of PHA producing bacterial strains for the isolation of potential strains.}

2.4.1. Screening of high $\mathrm{PHA}$ accumulating bacterial strains by using $\mathrm{N}^{0}-\mathrm{MSM}$ and $\mathrm{N}^{25}$ - MSM.

The cellulolytic and amylolytic bacterial strains which pro-duced PHA in Nile blue staining method were screened for higher quantity PHA accumulation. $1 \mathrm{~mL}$ of selected bacterial cultures were initially grown in $100 \mathrm{~mL}$ sterile MSM and incubated at $37^{\circ} \mathrm{C} / 100 \mathrm{rpm}$ with aeration for 48 hours for inoculum development. After incubation, spin at $5000 \mathrm{rpm}$ for 5 minutes at $4^{\circ} \mathrm{C}$. The supernatant was discarded and cell pellets were re-suspended with nitrogen-free MSM ( $\left.\mathrm{N}^{0}-\mathrm{MSM}\right)$. Then, transferred to $250 \mathrm{~mL}$ Erlenmeyer flask containing $100 \mathrm{~mL} \mathrm{~N}^{0}$-MSM. Another set were resuspended with $\mathrm{N}^{25}$ - MSM and transferred to $250 \mathrm{~mL}$ Erlenmeyer flask containing $100 \mathrm{~mL} \mathrm{~N} \mathrm{~N}^{25}$ - MSM. Both sets were incubated under an aerated condition at $37^{\circ} \mathrm{C} / 100 \mathrm{rpm}$ for 3 days. The PHA accumulation pattern was studied every 6 hours to 72 hours.

\subsubsection{Extraction of PHA.}

The sampling was performed every 6 hours. $10 \mathrm{~mL}$ of culture was taken and centrifuged at $5000 \mathrm{rpm}$ for 5 minutes. The supernatant was discarded and the cell pellet was treated with a dispersion containing $20 \mathrm{~mL}$ of $4 \%$ sodium hypochlorite and $10 \mathrm{~mL}$ of chloroform and incubated at $60^{\circ} \mathrm{C}$ in a water bath for overnight with intermittent vortexing. The sodium hypochlorite digestion process enables the complete digestion of cell components, degradation of lipids and the PHA granules release outside the cells are easy for the extraction of PHA (Shah, 2014). The mixture was centrifuged at $5000 \mathrm{rpm}$ for 5 minutes which resulted in three phases of separation. The upper phase was the aqueous sodium hypochlorite, the middle phasecontained the cell debris and the bottom contained organic chloroform phase with extracted PHA. The upper and middle phaseswerediscarded using a Pasteur pipette.

\subsubsection{PHA quantification by Ultraviolet-visible (UV-Vis)} Spectrophotometric method.

PHA was estimated by using UV- visible spectrophotometric method (Law and Slepecky, 1961). 100 $\mu \mathrm{L}$ of an aliquot of PHA containing chloroform was transferred into boiling tubes and dried at room temperature. Once dried, $10 \mathrm{~mL}$ of concentrated sulfuric acid $\left(\mathrm{H}_{2} \mathrm{SO}_{4}\right)$ was added into boiling tubes which having the polymer coating. The solution was heated in a boiling water bath for 20 minutes, cooled the solution and transferred to a quartz cuvette. Addition of sulfuric acid converts the PHB into crotonic acid which is brown colored. The absorbance was measured at $235 \mathrm{~nm}$ from the spectrum of $190 \mathrm{~nm}$ to $1000 \mathrm{~nm}$ against a sulfuric acid blank. The presence of PHA was confirmed by the peak at $235 \mathrm{~nm}$ 
$\left(\chi_{\max }\right)$. Positive bacterial strains which show maximum PHA accumulation were selected for next stage analysis. Positive bacterial strainswhich show maximum PHA accumulation were selected for the next stage analysis.

\subsection{Optimization of suitable condition for PHA ac- cumulation}

2.5.1. Further analysis of promising organism for PHA accumulation supplemented with sugar effluent.

One millilitre of the culture was initially grown in MSM and incubated at $37^{\circ} \mathrm{C} / 100 \mathrm{rpm}$ with aeration for 48 hours. The biomass was aseptically subjected to centrifugation at $5000 \mathrm{rpm}$ for $5 \mathrm{~min}-$ utes at $4^{\circ} \mathrm{C}$ to separate the biomass after incubation. The supernatant was discarded and cell pellets were centrifugally washed and re-suspended with a single strength of nitrogen-free and carbon-free MSM media (1X N $\left.{ }^{0} / \mathrm{C}^{0}-\mathrm{MSM}\right)$ and transferred to $250 \mathrm{~mL}$ Erlenmeyer flask containing $50 \mathrm{~mL}$ of $1 \mathrm{X} \mathrm{N}^{0} / \mathrm{C}^{0}$-MSM and $50 \mathrm{~mL}$ of sugar effluent without bacteriostatic antibiotic. Another flask was containing with $100 \mu \mathrm{g} / \mathrm{mL}$ of bacteriostatic antibiotic, chloramphenicol. Another set of bacterial biomass was resuspended and centrifugally washed with double strength $(2 \mathrm{X})$ of nitrogen and carbon-free MSM media ( $\left.2 \mathrm{X} \mathrm{N} / \mathrm{C}^{0}-\mathrm{MSM}\right)$. Then, transferred to $250 \mathrm{~mL}$ Erlenmeyer flask containing $50 \mathrm{~mL} 2 \mathrm{X}$ $\mathrm{N}^{0} / \mathrm{C}^{0}$-MSM and $50 \mathrm{~mL}$ of sugar effluent without chloramphenicol and another flask with chloramphenicol. The pattern of PHA accumulation was studied every 6 hours to 24 hours by using sugar effluent as carbon sources.

\subsubsection{Acetone drying and extraction of PHA from the se- lected strain.}

One millilitre of cultures of selected bacterial strainswas grown in full media of MSM (N100- MSM) and incubated at $37^{\circ} \mathrm{C} / 100 \mathrm{rpm}$ in aeration condition for 48 hours. After incubation, the bacterial biomass were subjected to centrifugation for $5000 \mathrm{rpm}$ for $5 \mathrm{~min}$ utes at $4{ }^{\circ} \mathrm{C}$. Then, the supernatant was discarded and cell pellets were re-suspended and centrifugally washed with MSM media with $25 \%$ of nitrogen $\left(\mathrm{N}^{25}-\mathrm{MSM}\right)$ and transferred to $250 \mathrm{~mL} \mathrm{Er}$ lenmeyer flask that contained $100 \mathrm{~mL}$ of $\mathrm{N}^{25}$-MSM and incubated at $37^{\circ} \mathrm{Cl} 100 \mathrm{rpm}$ in aeration condition for 12 hours. Bacterial biomass subjected into centrifugation for 5000rpm for 5 minutes at $4^{\circ} \mathrm{C}$ to separate the bio-mass after incubation. Bacterial biomass was centrifugally washed with acetone and kept under $-20^{\circ} \mathrm{C}$ for overnight. This step was repeated for 2 to 3 times using acetone and the mass was dried at room temperature after final washing.

\subsubsection{HPLC analysis of extracted PHA for Co-polymer Varia- tions}

Co-polymer variation in the positive strains was analysed by the method described by Rothermich et al., 2000.

\section{Results and discussion.}

Plastics are inevitable in everyday life in the form of disposable utensils, packaging, furniture, machinery housings and accessories, enhancing our life quality and comfort. Materials that made from synthetic polymers are not biodegradable and often discarded improperly. The best possible solutions are the environmentally biodegradable polymers known as biopolymers to replace the petroleum-based polymers (Wong et al., 2000). Among all various types of biodegradable plastics, polyhydroxyalkanoates (PHAs) are the most well-known. It has been being recognized as completely biosynthetic and biodegradable with zero toxic waste and completely recyclable into organic waste. Furthermore, PHAs are also microbial polyesters produced by the wide range of microorganisms mostly as intracellular storage compounds for energy and carbon (James et al., 1999). The major obstacle in facing commercial production of PHA is high production cost andhas been the major drawback to their replacement of petrochemicals plastics (Choi and Lee, 1997). In order to overcome this major hurdle, cheap carbon substrates have been used instead of high-cost glucose and other expensive carbon sources.

Table 1: Morphological, Biochemical and PHA accumulation characteristics features of isolated hetero-trophic bacterial strains

\begin{tabular}{|c|c|c|c|c|c|c|c|c|c|c|c|}
\hline $\begin{array}{l}\text { Strain } \\
\text { No. }\end{array}$ & Shape & Color & Form & Margin & Elevation & $\begin{array}{l}\text { Gram's } \\
\text { Stain } \\
\text { results }\end{array}$ & Morphology & $\begin{array}{c}\text { Amylolytic } \\
\text { activity }\end{array}$ & $\begin{array}{l}\text { Cellulolytic } \\
\text { activity }\end{array}$ & $\begin{array}{l}\text { PHA accu- } \\
\text { mulation }\end{array}$ & Scoring \\
\hline SE-01 & Rhizoid & White & Shiny & Rhizoid & Flat & + & Cocci & - & - & - & - \\
\hline SE-02 & Circular & Cream & Shiny & Entire & Convex & + & Rod & - & - & - & - \\
\hline SE-03 & Circular & Cream & Shiny & Entire & Convex & + & Cocci & - & - & - & - \\
\hline SE-04 & Irregular & Cream & Dull & Undulate & Flat & - & Cocci & - & - & - & - \\
\hline SE-05 & Circular & Cream & Shiny & Entire & Convex & + & Cocci & - & - & - & - \\
\hline SE-06 & Circular & Cream & Shiny & Entire & Convex & + & Rod & + & + & + & +++ \\
\hline SE-08 & Circular & Cream & Shiny & Entire & Flat & - & Cocci & - & - & - & - \\
\hline SE-09 & Circular & Cream & Shiny & Entire & Convex & + & Cocci & - & + & + & ++ \\
\hline SE-10 & Circular & Cream & Shiny & Curled & Convex & + & Rod & + & + & + & +++ \\
\hline SE-11 & Circular & Cream & Dull & Curled & Convex & - & Cocci & + & + & + & +++ \\
\hline SE-12 & Rhizoid & White & Dull & Curled & Flat & - & Cocci & + & + & + & +++ \\
\hline SE-13 & Circular & Yellow & Shiny & Entire & Pulvinate & - & Cocci & - & + & + & ++ \\
\hline SE-14 & Circular & Pink & Dull & Entire & Flat & - & Cocci & - & + & + & ++ \\
\hline
\end{tabular}

The most important factor in polyhydroxyalkanoates (PHAs) are the production process that known as the strategy of isolation and identification of suitable microorganism from the environment. Heterotrophic bacteria are known to be major soil bacteria where they derive all the carbons and energy from complex organic matter, decaying roots and plant residues. Moreover, this bacteria also use nitrogen and ammonia compounds that present in soil and other nutrients which derived from the soil as well or decomposing matter. Meanwhile, the heterotrophic native microflora was targeted from sugar effluent contaminated soil for this research work due to their ability to degrade organic substances like cellulose and starch with PHA accumulation capability.
3.1 Isolation and enumeration of heterotrophic native microflora from sugar mill effluent contaminated soil.

In the present study, bacterial isolates were obtained from sugar mill effluent contaminated soil that was collected from Central Sugar Refinery (CSR) SDN.BHD industry. The developed colonies on nutrient agar plates were counted and the mean number of colonies in triplicates of plates were determined. Table 2 shows the total heterotrophic bacterial load (CFU/g) of soil from the effluent contaminated site. The mean value of total bacterial counts was considerably high for the effluent contaminated soil samples. A total of 14 different heterotrophic native microflora 
were isolated on the basis of differential morphology and gram's reaction which shown in Table 1.

\subsection{Screening of bacterial strains for amylolytic and cel- lulolytic activity.}

Heterotrophic bacterial isolates were primarily screened for the production for amylolytic and cellulolytic enzyme activity by Gram's iodine and Congo red assay respectively. As shown in Figure 1, out of 14 strains, 4 strains showed clear zones around the corresponding colonies after adding Gram's iodine solution. As for cellulolytic activity, atotal of 7 strains were found positive upon Congo red staining that producing clear zone as shown in Figure 2. This procedure has been repeated for the plates that incubated for 48 hours, 72 hours, 96 hours and 120 hours. This is because a slow-growing organism was found positive after 72 hours.

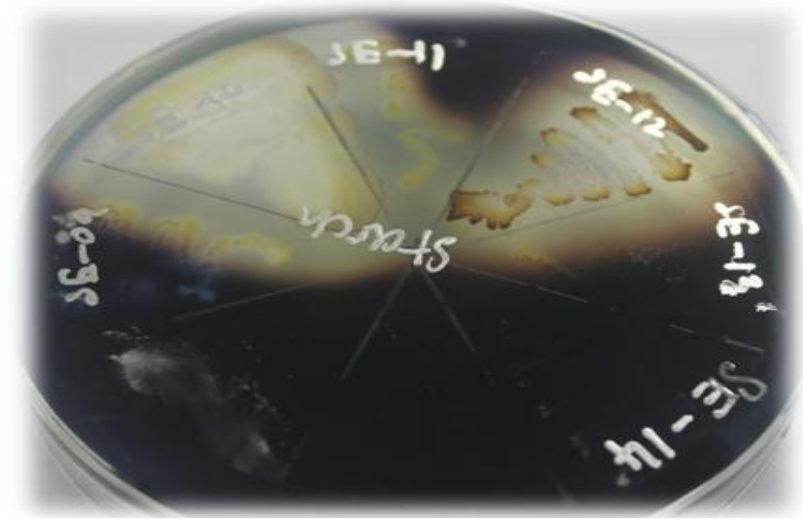

Fig. 1: Selective screening of starch hydrolyzing heterotrophic bacteria on the plates incubated for 96 hours. Bacterial colonies of SE-09 to SE12 showing clear zones after staining with Gram's iodine are marked as amylase positive

The soil samples collected from sugar effluent contaminated area were enriched with the functional microbial population as it indicated the high population of amylolytic and cellulolytic bacteria which shown in Table 3 . The purpose of screening cellulolytic andamylolytic bacteria in sugar effluent is that it contains many organic compound such as the volatile fatty acid (VFA) and total suspended solids (TSS). Besides that, the microorganism mediated the processes through enzymatic activities of cellulose and amylase can efficiently convert these organic compounds intoa simpler compound. Thus, it provides the substrate for the production of polyhydroxyalkanoates (PHAs) (Subin et al., 2013).

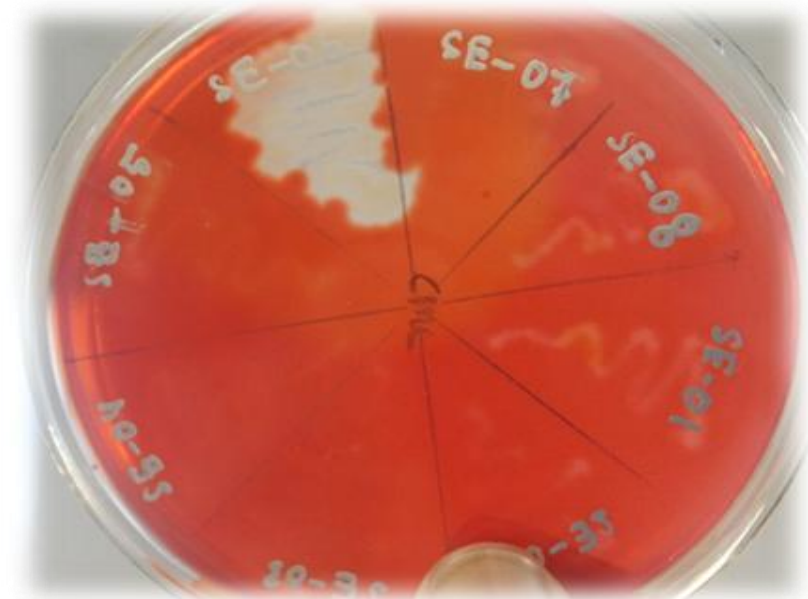

Fig. 2: Zone of clearance on cellulose Congo red assay for isolates after 72 hours of incubation. The formation of a clearing zone around the colonies confirmed the secretion of extracellular cellulase

\subsection{Isolation and screening of bacterial strains for PHA accumulation}

The preliminary screening for PHA accumulation for all the 14 amylolytic and cellulolytic positive bacterial strains was carried out on Mineral salt media (MSM) plate with varying nitrogen concentration since the bacteria are known to accumulate the PHA granules in cells on the nitrogen deficient condition. The ability of bacterial strains to produce intracellular PHA granules was confirmed by using the Nile blue-A staining method. The bacterial strains containing granules were observed as bright orange fluorescence on irradiation with UV light and their fluorescence intensity increased with increase in PHA content of bacterial cells which has shown in Figure 3.

\subsection{Quantification of PHA by Ultraviolet-visible (UV- Vis) Spectrophotometry}

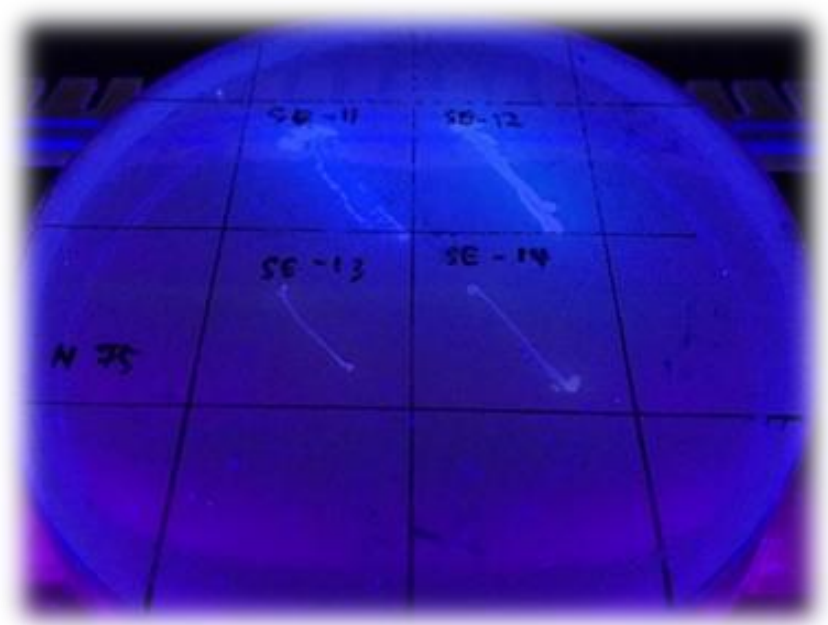

Fig. 3: Preliminary screening by Nile blue-A on MSM agar at $\mathrm{C}$ : $\mathrm{N}$ ratio of 100: 75. Bright orange fluorescence was observed under UV light by PHA accumulated isolates of SE-06 and SE-09 to SE-14

The three strains that have been selected (SE-10. SE-11 and SE-12) were screened in the nitrogen-free MSM media $\left(\mathrm{N}^{0}\right)$ and MSM media with the nitrogen content of $25 \%\left(\mathrm{MSM}-\mathrm{N}^{25}\right)$. The accumulation of PHA was tested by spectrophotometric method for both strains that shown in Figure 4. Comparison of UV-Vis spectrum obtained for the selected PHA producers with the standard PHB was made. The spectrophotometric assay was performed with the polymer extracted from the strain SE-10, SE-11 and SE-12 and the standard were analysed after the digestion with sulfuric acid $\left(\mathrm{H}_{2} \mathrm{SO}_{4}\right)$. The digestion with sulfuric acid, hydroxybutyric acid converted into crotonic acid that has the maximum absorption at 235nm (Law and Slecpecky, 1961). Thus, the complete matching of thespectra of an acid-digested sample and the standard shows the presence of PHA in the strain SE-10, SE-11 and SE-12

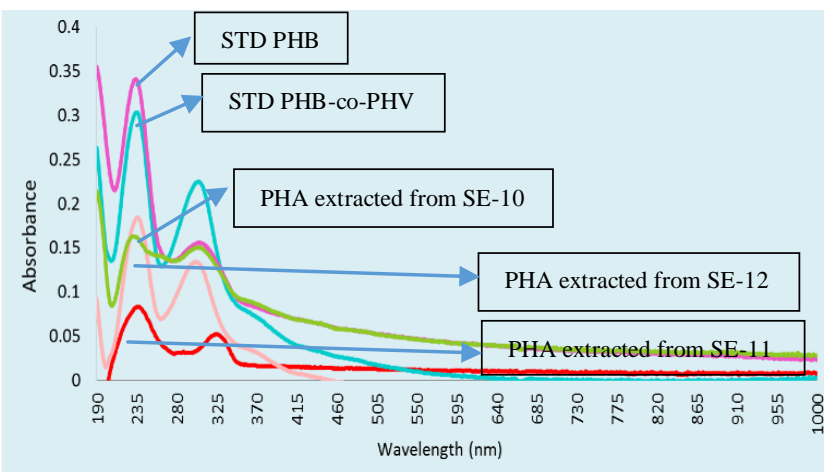

Fig4: Ultraviolet-Visible overlay spectrum of extracted PHA from strain SE-10, SE-11 and SE-12 


\subsection{Analysis of PHA accumulation pattern for selected strains in $\mathrm{N}^{0}$-MSM and $\mathrm{N}^{25}$-MSM.}

The selected two strains (SE-10. and SE-12) were cultured in $\mathrm{N}^{0}$ MSM and $\mathrm{N}^{25}$-MSM and the time course of PHA accumulation pattern was monitored for every 6 hours to 72 hours of the incubation period. The amount of PHA being converted into crotonic acid varied among both strains that have shown in Figure 5 and Figure 6. The SE-10 strain showed low PHB content as low as $3.26 \mu \mathrm{g} / \mathrm{mL}$ of culture at 72 hours and showed a higher rate of PHA content into crotonic acid as high as $93.95 \mu \mathrm{g} / \mathrm{mL}$ of culture Whereas, the SE-12 strain showed low PHB content as low as $4.65 \mu \mathrm{g} / \mathrm{mL}$ of culture at 72 hours and showed a higher rate of PHB content at $137.20 \mu \mathrm{g} / \mathrm{mL}$ of culture. The PHB content indicates the total amount of PHA which has been accumulated by the bacterial strains at a specific hour.

Graph of PHA content against time in hour for strain SE-10.

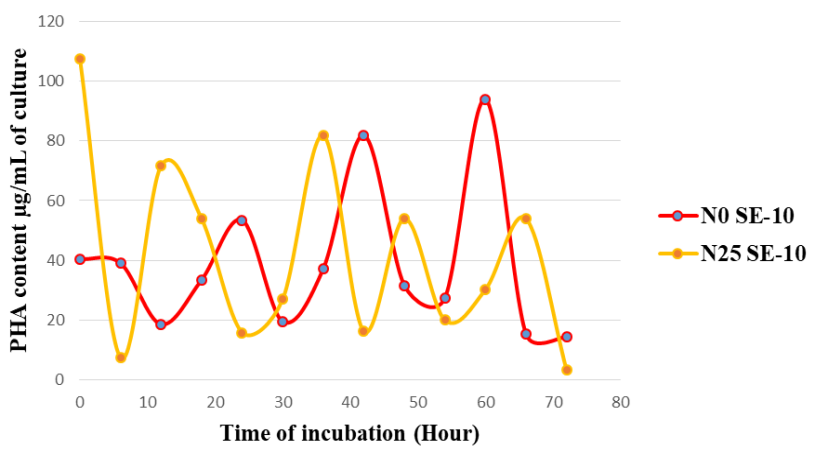

Fig. 5: Quantitative analysis of crotonic acid derived from extracted PHA of SE-10.

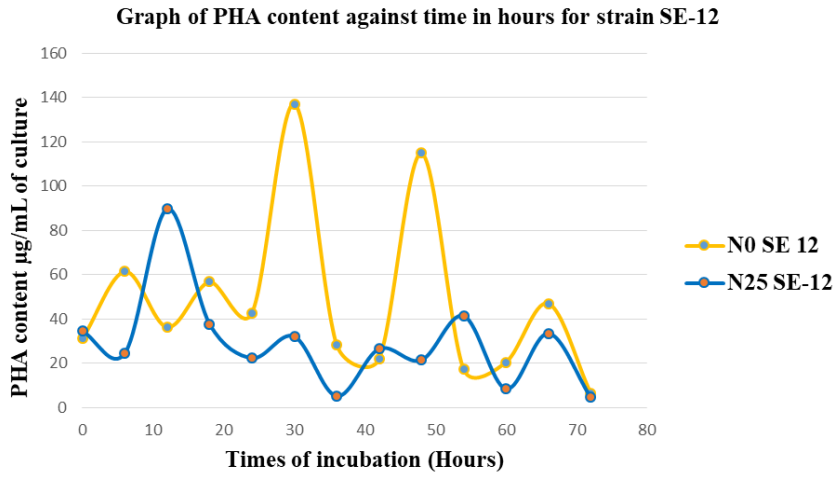

Fig. 6: Qualitative analysis of crotonic acid derived from extracted PHA of SE-12.

Both bacterial strains were able to accumulate the amounts of PHA with glucose as primary carbon sources in the nitrogen-free medium as well as in $25 \%$ of nitrogen content medium $\left(\mathrm{N}^{25}\right.$ MSM). The accumulation of PHA was observed from 0 hours in which the graph shows slight increases in the PHA content for the 6 hour to 12 hours and reach a maximal peak around 30 hours to 48 hours. There was a decline in the PHA content on further incubation, showing that the carbon source was being utilized by the bacteria for the growth and PHA production. Based on Figure 5 and Figure 6, shows that the maximum amount of PHA accumulation varies among the bacterial strains and both strains showed the highest peak at $30^{\text {th }}$ to $48^{\text {th }}$ hours.

In Figure 6, it was found that the PHA accumulation for SE-12 strain cultured in $\mathrm{N}^{25}$ - MSM started after 6 hours and continued increasing until 12 hours where the graph showed an increase in PHA content from $24.65 \mu \mathrm{g} / \mathrm{mL}$ of culture at the $6^{\text {th }}$ hour to $89.76 \mu \mathrm{g} / \mathrm{mL}$ of culture by the $12^{\text {th }}$ hour. This is because PHA was produced and accumulated in granules where the maximum production of PHA was obtained $89.76 \mu \mathrm{g} / \mathrm{mL}$ of culture within 12 hour of fermentation. Besides that, the PHA content was started to decrease after 12 hour due to bacteria could synthesize PHA until certain stage

Among the 2 strains analysed in $\mathrm{N}^{0}$-MSM and $\mathrm{N}^{25}$-MSM, both bacterial strains showed the maximum amount of PHA accumulation in a specific hour that shown in Table 2 and considered as potential PHA producers. This preliminary experiment with glucose as primary carbon sources that allowed the selection of best PHA producing bacteria based on the duration and PHA content and they were further tested with sugar effluent as a carbon source in a different condition of MSM supplement with the bacteriostatic antibiotic. The selected isolates were SE-10 and SE-12 shows maximal PHA accumulationat the $12^{\text {th }}$ hour of incubation in $\mathrm{N}^{25}$-MSM. This infers the suitability of the strain for further work and can primarily be assumed as promising strain due to its faster productivity

Limitation of nutrients such as nitrogen, phosphorus and certain other elements greatly increased the polymer accumulation rate in most bacterial PHA synthesis (Wen et al., 2010). The lack of essential nutrients, including nitrogen can cause the growth restriction and physiological changes, through which the cells try to optimize the scavenging of nutrients and growth (Chinwetkitvanich, 2004).

\subsection{Analysis of PHA accumulation pattern for selected strain by using sugar effluent.}

Usage of sugar effluent for the production of PHA remains as an attractive strategy due to their high carbon content particularly volatile fatty acids (VFA) content that shown in Table 1 . Thereby have the chance of increasing the yield of the products. In addition, heterotrophic bacteria are found to possess the ability to metabolize organic and toxic compounds. Therefore, the present study analyses effect of sugar effluent on the production of PHA in the selected strain

The production of PHA was evaluated with two different sources such as sugar effluent and bacteriostatic antibiotic, chloramphenicol under different culture condition of the single and double strength of nitrogen free mineral salt media ( $1 \mathrm{X}$ and $2 \mathrm{X}$ nitrogen free MSM). The bacteriostatic antibiotic, chloramphenicol is given in order to inhibit the growth of the organism and it acts as a stress condition towards the organism to produce a high yield of PHA. Moreover, the limited condition of nitrogen and excessive carbon sources could lead to higher production of PHA (Rehm, 2010). The total PHA accumulation pattern was shown in Figure 8 shows that the organism is able to utilize the carbon sources from the sugar effluent for the PHA accumulation. However, the usage of the sugar effluent as carbon sources showed gradual increases of PHA content in $1 \mathrm{X} \mathrm{N}^{0}$-MSM without chloramphenicol by comparing $1 \mathrm{X} \mathrm{N}^{0}$-MSM with chloramphenicol that shown in Figure 7. There is higher PHA content of $99.99 \mu \mathrm{g} / \mathrm{mL}$ of culture at 6 hours in $2 \mathrm{X} \mathrm{N}^{0}$-MSM without chloramphenicol condition compared to $2 \mathrm{X} \mathrm{N}^{0}$-MSM with chloramphenicol. This is because heterotrophic native microflora surrounds the environment has the capability to utilize the effluents and their derivative products for metabolism and convert them to the compound such as storage materials within the bacterial cell.

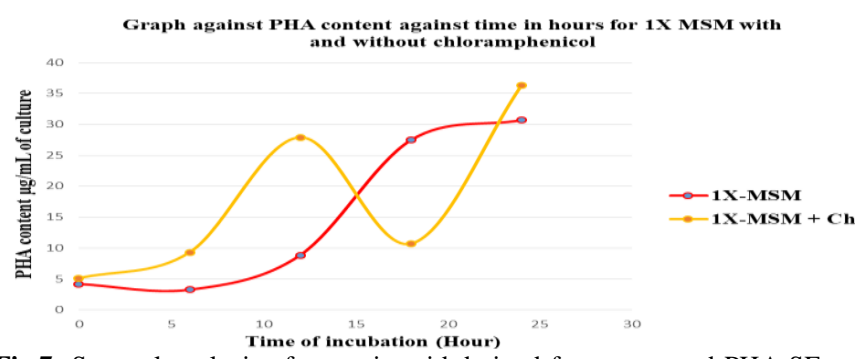

Fig.7: Spectral analysis of crotonic acid derived from extracted PHA SE12 in single strength nitrogen free MSM (1X $\mathrm{N}^{0}$-MSM) supplement with sugar effluent and chloramphenicol. 
The selected strain SE-12 was able to accumulate PHA content about $99.99 \mu \mathrm{g} / \mathrm{mL}$ culture in double strength MSM that has supplement with sugar effluent at the $6^{\text {th }}$ hour. However, for $1 \mathrm{~L}$ of culture, approximately $0.9 \mathrm{~g}$ of PHA was able to accumulate within 6 hour

The production of PHA with nitrogen limited condition from this study was comparatively summarized in Table 2 . The organism showed the highest PHA accumulation, absorbance value of 0.215 units at $\chi \max 235 \mathrm{~nm}$ in double strength nitrogen free condition. This strain was able to accumulate the longer amount of PHA within a shorter duration of time $\left(6^{\text {th }}\right.$ hour $)$ compared to other conditions. Hence, it can be considered as effective PHA producer and promising strain for further analyses. Yet, it is essential to analyze the co-polymer which present in this strain in order to use it for biomedical application.

\subsection{HPLC Analysis of PHA samples for Copolymer variations}

The Potential strains which showed positive for PHA accumulation were further subjected to HPLC analysis to check their ability to accumulate PHB and PHV copolymer. The HPLC chromatogram (Fig. 8) showed the peak for standard PHB-Co-PHV and the chromatogram (Fig. 9) shows the peak for PHB-co-PHV (7:3) of selected strain SE-12. Among the seven strains, four strains (SE-06, SE-09,SE-13 and SE-14) accumulated only PHB whereas threestrains (SE-10, SE-11 and SE-12) accumulated PHB-co-PHV were confirmed.

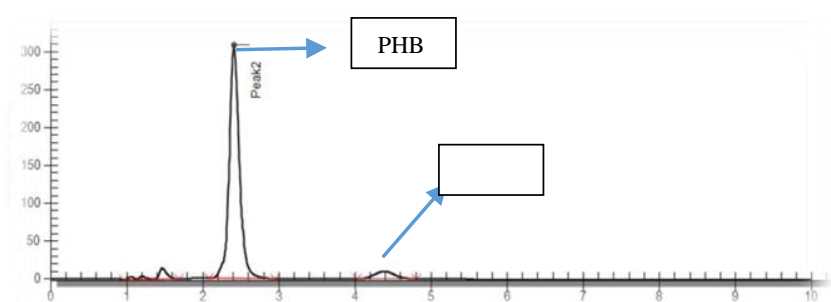

Figure 8: HPLC chromatogram showing the peaks for PHB and PHV standard sample

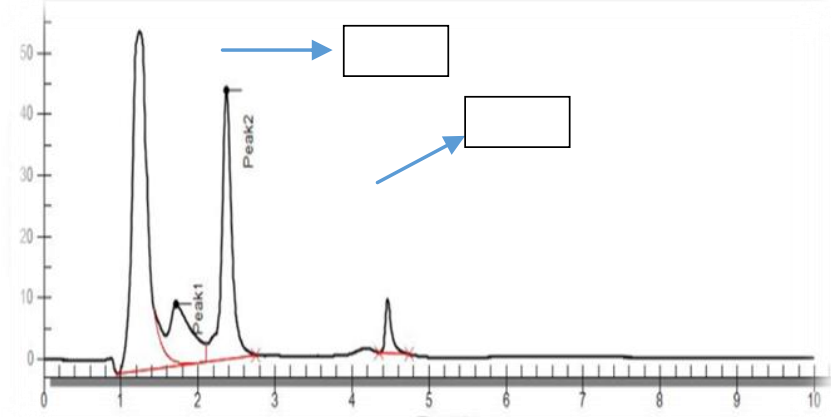

Figure 9: HPLC chromatogram showing the peaks for PHB and PHV of selected strain SE-12

Table 2: The suitable condition of selected PHA producer for highest PHA accumulation

\begin{tabular}{|c|c|c|c|c|}
\hline $\begin{array}{l}\text { Strain } \\
\text { No. }\end{array}$ & Condition & $\begin{array}{l}\text { Time of incuba- } \\
\text { tion (h) for } \\
\text { maximal PHA } \\
\text { achieved }\end{array}$ & $\begin{array}{l}\text { Absorbance } \\
\text { at } 235 \mathrm{~nm}\end{array}$ & $\begin{array}{l}\text { PHA con- } \\
\text { tent ( } \mu \mathrm{g} / \mathrm{mL} \\
\text { of culture) }\end{array}$ \\
\hline \multirow[t]{5}{*}{ SE-12 } & $\begin{array}{l}1 \mathrm{XN}^{0}- \\
\mathrm{MSM}^{-}\end{array}$ & 24 & 0.66 & 30.70 \\
\hline & $1 \mathrm{X} \mathrm{N}^{0-}$ & 24 & 0.078 & 36.28 \\
\hline & $\begin{array}{l}\mathrm{MSM}+ \\
\mathrm{AB}\end{array}$ & & & \\
\hline & $\begin{array}{l}2 \mathrm{X} \mathrm{N}^{0}- \\
\mathrm{MSM}^{-}\end{array}$ & 6 & 0.215 & 99.99 \\
\hline & $\begin{array}{c}2 \mathrm{X} \mathrm{N}^{0}- \\
\mathrm{MSM}+ \\
\mathrm{AB}\end{array}$ & 12 & 0.063 & 29.30 \\
\hline
\end{tabular}

\subsection{Strain identification by 16s rRNA sequencing.}

The selected strain, SE-12, was identified by 16 s rRNA technique and it was confirmed asChryseobacterium Sp. The sequence of this strain is approximately $99 \%$ similarity with Chryseobacteriumgallinarum. Chryseobacterium genus comprises of many species from different sources (Vandammeet al., 1994). However, there is no any studies conducted using this bacteria for the production of PHA. For example, genetically engineered bacteria such as recombinant strains of Escherichia coli was able to produce $\mathrm{PHA}$ containing $3 \mathrm{HB}, 3 \mathrm{HHx}$ and $3 \mathrm{HO}$ monomers from soybean oil.

\section{Conclusion}

The main objective of the study was the production of polyhydroxyalkanoates (PHAs) with the help of the industry wastes as a carbon source in order to reduce the cost of commercial PHA production. The sugar wastes contaminated ecosystem produced 2 optimum PHA producing bacteria, one of the isolates, Chryseobacteriumgallinarum, and produced maximal amount of PHA with PHB: PHV in the ratio of 7:3 in nitrogen deficient condition and double strength MSM with sugar effluent in a shorter duration of time. It could be utilized to achieve cost-effective production of biodegradable polymers with further optimization of fermentation condition.

\section{Acknowledgement}

The authors thank MAHSA University for providing all support. We also thank other team-mates for valuable assistance during the work

\section{References}

[1] Chinwetkitvanich S, Randall, CW. and Panswad T (2004). Effects of phosphoruslimitation and temperature on PHA production in activatedsludge. Water Science and Technology 50(8), 135-143.

[2] Choi JI, and Lee SY, (1997). Process analysis and economic evaluation for poly (3-hydroxybutyrate) production by fermentation. $\mathrm{Bi}$ oprocess and Biosystems Engineering 17(6), pp.335-342.

[3] Flieger M, Kantorova M, Prell A, Rezanka T, and Votruba J (2003). Biodegradable plastics from renewable sources. Folio Microbiology, 48, 27-44.

[4] James BW, Mauchline W S, Dennis PJ, Keevil CW and Wait R. (1999). Poly-3-hydroxybutyrate in Legionella pneumophila, an energy source for survival in low nutrient environments, Applied Environmental Microbiology 65, 822-827.

[5] Johnsen HR, and Krause K, (2014). Cellulase activity screening using purecarboxymethylcellulose: application to soluble cellulolytic samples and to planttissue prints. International Journal of Molecular Sciences, 15(1), pp.830-838.

[6] Khanna S. and Srivastava AK (2009). On-line characterization of physiological state in poly (hydroxybutyrate) production by Waustersiaeutropha. Applied Biochemistry. Biotechnology, 157(2) 237-43.

[7] Kitamura S. and Doi Y. (1994). Staining method of poly (3hydroxyalkanoic acids) producing bacteria by Nile blue. Biotechnology techniques, 8(5), pp.345-350.

[8] Law JH, and Slepecky RA (1961). Assay of poly- $\beta$-hydroxybutyric acid. Journal of Bacteriology, 82(1), pp.33-36.

[9] Law KH, Cheng YC, Leung YC, Lo WH, Chua H, and Yu HF (2003). Construction of recombinant Bacillus subtilis strains for polyhydroxyalkanoates synthesis. Biochemistry Engineering Journal 16, 203-208.

[10] Lee SY (1996). Plastic bacteria. Progress and prospects for polyhydroxyalkanoate production in bacteria. Trends Biotechnology, 14, 431-438.

[11] Mishra S. and Behera N. (2008). Amylase activity of a starch degrading bacteria isolated from soil receiving kitchen wastes. African Journal of Biotechnology, 7(18). 
[12] Nath A, Dixit M, Bandiya A, Chavda S and Desai AJ (2008). Enhanced PHB production and scale up studies using cheese whey in fed batch culture of Methylobacterium sp. ZP24. Bioresource technology, 99 (13), pp.5749-5755.

[13] Otari SV and Ghosh JS (2009). Production and characterization of the polymerpolyhydroxybutyrate-co-polyhydroxyvalerate by Bacillus megaterium NCIM 2475. Current Research Journal of Biological Sciences, 1(2), pp. 23-26.

[14] Paulraj P, Vnootheni N, Chandramohan M, and Javad PTM (2018). Exploration of Global Trend on Biomedical Application of Polyhydroxyalkanoate (PHA): A Patent Survey. Recent Patents in Biotechnology 12, 186-189.

[15] Rehm BH (2010). Bacterial polymers: biosynthesis, modifications and applications. Nature reviews. Microbiology. 8(8), p.578.

[16] Rothermich MMR,Guerrerro, RW, Lenz S. Goodwin(2000).Characterization, seasonal occurrence, and diel fluctuation of poly(hydroxyalkanoate) in photosynthetic microbial mats. Applied and Environmental Microbiology. 66(10) 4279-4291

[17] Shah KR (2014). Optimization and production of Polyhydroxybutarate (PHB) by Bacillus subtilis G1S1 from soil. International Journal of Current Microbiology Applied Sciences, 3(5), pp.377-387.

[18] Steinbuchel A (2001). Perspectives for biotechnological production and utilization of biopolymers: Metabolic engineering of polyhydroxyalkanoate biosynthesis pathways as a successful example. Macromolecular Biosciences1, 1-24.

[19] Subin RS, Varghese SM and Bhat SG (2013).Isolation and characterization of polyhydroxyalkanoates accumulating Vibrio sp. strain BTTC26 from marine sediments and its production kinetics. Journal of Scientific and Industrial Research, pp. 228-235.

[20] Vandamme P, Bernardet JF, Segers P, Kersters K and Holmes B (1994). New Perspectives in the Classification of the Flavobacteria: Description of Chryseobacterium gen. nov., Bergeyella gen. nov., and Empedobacter nom. rev. InternationalJournal of Systematic and Evolutionary Microbiology, 44(4), pp.827-831.

[21] Verlinden RA, Hill DJ, Kenward MA, Williams CD and Radecka I (2007). Bacterial synthesis of biodegradable polyhydroxyalkanoates Journal of Applied Microbiology, 102(6), pp.1437-1449.

[22] Wen Q, Chen Z, Tian T. and Chen W (2010). Effects of phosphorus and nitrogen limitation on PHA production in activated sludge. Journal of Environmental Sciences, 22(10), pp.1602-1607.

[23] Wong AL, Chua H, and Yu PHF (2000). Microbial production of polyhydroxyalkanoates by bacteria isolated from oil wastes, Applied Biochemistry Biotechnology 84, 843-857.

[24] Xiong YC, Yao YC, Zhan XY, and Chen GQ (2010). Application of polyhydroxyalkanoates nanoparticles as intracellular sustained drug-release vectors. Journal of Biomaterial Sciences, Polymer Edition, 21(1), pp. 127-140. 